\title{
The Antioxidant Flavonoids, Orientin and Vicenin Enhance Repair of Radiation-Induced Damage
}

\author{
Satyamitra $\mathrm{M}^{1^{*}}$, Mantena $\mathrm{S}^{2}$, Nair $\mathrm{CKK}^{3}$, Chandna $\mathrm{S}^{4}$, Dwarakanath $\mathrm{BS}^{4}$ and Uma Devi $\mathrm{P}^{5}$ \\ ${ }^{1}$ Department of Radiobiology, Kasturba Medical College, Manipal, India \\ ${ }^{2}$ Department of Environmental Health Sciences, School of Public Health, University of Alabama, Birmingham, United States \\ ${ }^{3}$ Amala Cancer Research Center, Amalanagar, Trichur, Kerala, India \\ ${ }^{4}$ Division of Radiation Biosciences, Institute of Nuclear Medicine and Allied Sciences, Delhi, India \\ ${ }^{5}$ ARA-B-35A, Plavilakonam, Thachottukavu, Peyad P.O., Trivandrum, India
}

*Corresponding author: Satyamitra M, Bethesda, MD 20889, USA, Fax: +1 3012956903, Tel: +1 3012959226, E-mail: merriline.satyamitra.ctr@usuhs.edu

Citation: Satyamitra M, Mantena S, Nair CKK, Chandna S, Dwarakanath BS, et al. (2014) The Antioxidant Flavonoids, Orientin and Vicenin Enhance Repair of Radiation-Induced Damage. SAJ Pharma Pharmacol 1: 105. doi: $10.18875 / 2375-2262.1 .105$

Article history: Received: 17 June 2014, Accepted: 27 June 2014, Published: 20 August 2014

\begin{abstract}
Orientin (Ot) and vicenin (Vc), two water soluble flavonoids isolated from the Indian Holy Basil, are potent radioprotectants, but the mechanisms of protection are not fully understood. In the present study, we investigated the effects of these flavonoids as antioxidants in chemical systems and plasmid DNA and radioprotectants in bacterial and mammalian cells. The radical scavenging activities of Ot and Vc were assessed in two chemical systems, dipehnylpicrylhydrazyl (DPPH) and 2,2'-azino-bis(3-thylbenz-thiazoline-6-sulfonic acid) (ABTS) by estimating absorbance at 517 and $734 \mathrm{~nm}$, respectively. Protection by the flavonoids against $\mathrm{H}_{2} \mathrm{O}_{2}(30 \mathrm{mM})$ damage to plasmid pGEM-7Zf was assessed by DNA electrophoresis. Effect of flavonoid pre-treatment on survival of irradiated (30-150 Gy $\gamma$-rays) repair proficient (AB1157) and repair deficient (MD2130) E.coli cells was assayed. Furthermore, induction and repair of DNA damage to 4 Gy irradiated mouse splenocytes was analyzed using the comet assay. Ot and Vc significantly scavenged DPPH and ABTS. Both flavonoids protected plasmid pGEM-7Zf in the nicked circular form following $\mathrm{H}_{2} \mathrm{O}_{2}$ treatment. Pretreatment with $200 \mu \mathrm{M}$ of either flavonoid significantly increased clonogenic survival of repair proficient cells at all radiation (RT) doses; in repair deficient strain, protection was significant at the lower RT doses (30 and $50 \mathrm{~Gy}, \mathrm{p}<0.01$ ). Ot and Vc significantly reduced 4 Gy-induced DNA damage and allowed for faster repair of ex-vivo irradiated mouse splenocytes.

These studies underscore the potent antioxidant activity of orientin and vicenin; in addition, both flavonoids appear to facilitate repair of radiation-induced injury.
\end{abstract}

Keywords: Orientin; Vicenin; Radical scavenging; DNA protection; Bacterial survival; Comet assay

\section{Introduction}

Ionizing radiations cause damage to the DNA, lipids and proteins, resulting in perturbation of cell signaling pathways, cell-cycle disruption, apoptosis, mitotic death, or necrosis. The role of radioprotective compounds in mitigating the structural and functional damage to normal tissues in the event of planned exposures or radiation accidents has been studied extensively for more than half a century [1-3]. To date, there are no FDA-approved countermeasures to prevent or treat acute radiation syndrome.

Ocimum sacntum (also known as the Indian Holy Basil) is used by medicinal practitioners for its antidiabetic, antifungal, antimicrobial, analgesic, and anticancer potential [4]. Orientin (Ot) and vicenin (Vc) are water soluble c-glycoside flavonoids isolated from the aqueous leaf extract of Ocimum sanctum. Ot and Vc have demonstrated potent radioprotective activity in vivo at low non-toxic doses with dose reducing factors of 1.3 and 1.37, respectively [5] and excellent hydroxyl radical scavenging activity in vitro [5,6]. Further, we have reported that treatment of pregnant mice with $50 \mu \mathrm{g} / \mathrm{kg}$ body weight of either Ot or Vc prior to irradiation significantly reduced radiation-induced chromosomal anomalies in fetal and adult hematopoietic cells, and restored blood indices to normal range in the off-spring; while radiation-induced solid tumor incidence was significantly reduced [7]. On the basis of the authors' own studies and other publications, several mechanisms such as radical scavenging, metal chelation, 
release of cellular antioxidants, DNA repair, and immunomodulation have been proposed to explain the radioprotective effects of Ocimum extract and its flavonoids [8]. Experimental data are available on the antioxidant and metal chelating activities of Ot and Vc in chemical systems [6,9] and in Escherichia coli [10], while immune-modulatory effect is reported for the crude extract [11]. Further, oral cancer patients undergoing radiation therapy and treated with the ocimum flavonoids demonstrated significant increase in leukocyte antioxidants compared to the group receiving irradiation alone [12].

An ideal radioprotector should be effective against acute - and long-term radiation effects, non-toxic, affordable, and be chemically stable to permit ease of handling and storage. Our goal was to use a battery of different assays that complemented each other to further understand the role of Ot and Vc in protecting against chemical- and radiation-induced damage. Free radical scavenging was confirmed by the DPPH and ABTS assays and in plasmid DNA; DNA strand break and clastogenicity was studied in DNA plasmid and bacterial cells. The efficacy of Ot and Vc in repairing radiation-induced DNA strand breaks in mouse splenocytes was measured by the comet assay.

\section{Materials \& Methods}

\section{Materials}

Materials were purchased from the following sources: Eagles minimum essential medium, fetal calf serum, low melting point and normal agarose, DPPH and ABTS from Sigma-Aldrich, St Louis, MO, USA. Luria broth, Luria agar and Hank's balanced salt solution from Himedia, Mumbai, India.

Plasmid pGEM-7Zf and E. coli were provided by Dr. Sathyamoorthy, Department of Cell and Molecular Biology, Kasturba Medical College, Manipal, India.

The bacterial strains AB1157 (repair proficient) and MD2130 (repair deficient) were kindly provided the Radiation Biology Division, Bhabha Atomic Research Center (BARC, Mumbai, India).

\section{Isolation of Ocimum flavonoids}

Fresh leaves of the dark variety of Ocimum sanctum (Sanskrit: Tulasi, English: Indian Holy Basil) were collected locally, washed and shade-dried. An aqueous extract was prepared by refluxing the powder with double-distilled water at $80{ }^{\circ} \mathrm{C}$ and condensed in a vacuum drier (Speedvac SC 110 A, MN, USA). The active components were isolated from the extract by chromatographic separation and their identity confirmed using Nuclear Magnetic Resonance (NMR) spectroscopy [5].

\section{Preparation of Drug Solution}

Both Ot (Mol. wt. 448) and Vc (Mol. Wt. 594) are stable at room temperature. The drug solutions were freshly prepared by dissolving appropriate quantities of the two compounds in double-distilled water (DDW) under sterile conditions shortly before use.

\section{Animals}

Healthy, 8-12 weeks old BALB/c male mice, weighing $29 \mathrm{~g}$, from the inbred colony at the Institute of Nuclear Medicine and Allied Sciences (INMAS), Delhi, India were used. The mouse splenocytes were collected as described under methods [13].

\section{Irradiation}

Bacteria were exposed on ice in sterile $2 \mathrm{~mL}$ stoppered tubes (Nunc, Germany) in a field size of $10 \mathrm{x} 20 \mathrm{~cm}^{2}$ at a source to sample distance of $60 \mathrm{~cm}$ and dose rate of $3.6 \mathrm{~Gy} / \mathrm{min}$ using a cobalt-60 teletherapy unit (Siemens, Germany) in the Department of Radiotherapy and Oncology, Shirdi Sai Baba Cancer Hospital and Research Center, Manipal.

Mouse splenocytes were exposed to gamma rays on ice in sterile Petri dishes (Nunc, Germany) using a ${ }^{60}$ Co teletherapy unit (Eldorado, Theratron 780C, AECL, Canada) at a source to sample distance of $80 \mathrm{~cm}$. The dose rate was $1.4 \mathrm{~Gy} / \mathrm{min}$. All animal studies were conducted according to the institutional regulations and national criteria for animal experimentation.

\section{Experimental Procedures}

The following experiments were conducted

Radical scavenging activity in chemical systems: These following two chemical tests were conducted to validate the antioxidant activity of the flavonoids isolated from the Indian Holy Basil.

Scavenging of 1,1-diphenyl-2-picrylhydrazyl (DPPH): DPPH, a stable free radical characterized by a deep violet color, is reduced to a pale yellow to colorless form, dipicrylhydrazine, in the presence of antioxidants [14], with a concomitant decrease in absorbance at $517 \mathrm{~nm}$. DPPH $(96 \mu \mathrm{M})$ in DMSO was mixed well with Ot or Vc at different concentrations $(0-250 \mu \mathrm{M})$ to give a final volume of $1.0 \mathrm{~mL}$ and the reaction mixture was placed in the dark at room temperature for $20 \mathrm{~min}$. Absorbance was recorded at $517 \mathrm{~nm}$. The antiradical activity is mea-sured by the percentage of inactive DPPH: 
Inactive percentage $=[(\mathrm{Ab}-\mathrm{Aa}) / \mathrm{Ab}] \mathrm{X} 100$; where $\mathrm{Ab}$ is the absorption of a blank specimen at $\mathrm{t}=0 \mathrm{~min}, \mathrm{Aa}$ is the absorption of $\mathrm{Ot}$ or $\mathrm{Vc}$ in the reaction mixture.

Scavenging of 2,2'-azino-bis(3-ethylbenzthiazoline-6-sulfonic acid) cation (ABTS): The ABTS assay is based on the oxidation of ABTS to an intensely-colored nitrogen-centered radical cation, $\mathrm{ABTS}^{*}$ by antioxidants, which has a characteristic long-wavelength absorption maxima at $734 \mathrm{~nm}[15]$.

The reaction mixture contained ABTS radical [ABTS $(2 \mathrm{mM})$, potassium persulphate $(0.17 \mathrm{mM})$ ], various concentrations of Ot or $\mathrm{Vc}(0-80 \mu \mathrm{M})$ in PBS buffer $(\mathrm{pH} 7.4,20 \mathrm{mM})$ in a total volume of $3.5 \mathrm{~mL}$. Absorbance was recorded at $734 \mathrm{~nm}$.

The antiradical activity was calculated by applying the same formula as for the DPPH assay. Both assays were repeated and percent inhibition of DPPH and ABTS calculated. The data presented are mean \pm SEM (standard error of mean) of three separate experiments. The $\mathrm{IC}_{50}$ values for both assays (the concentration of flavonoids required to inhibit either DPPH or ABTS activity by $50 \%$ ) were calculated from the concentration-inhibition linear regression curves [14].

DNA nicking assay for radical scavenging activity: All experiments were conducted in potassium phosphate buffer $(\mathrm{pH} 7.4$, $50 \mathrm{mM}$ ). Two $\mu \mathrm{L}$ each of ethylenediaminetetraacetic acid (EDTA), phosphate buffer, $\mathrm{H}_{2} \mathrm{O}_{2}(30 \mathrm{mM}), \mathrm{FeSO}_{4}(16 \mathrm{mM})$, Ot or Vc $(250 \mu \mathrm{M})$ and plasmid pGEM-7Zf DNA $(0.1 \mu \mathrm{g} / \mu \mathrm{L})$ were mixed in a $500 \mu \mathrm{L}$ tube. The final volume of the reaction mixture was brought to $12 \mu \mathrm{L}$ with deionized DDW and incubated for $1 \mathrm{~h}$ at $37^{\circ} \mathrm{C}$. Following incubation, $2 \mu \mathrm{L}$ loading dye (6XEESB-20XTEA buffer, glycerol, bromophenol blue, xylene cyanole and water) was added and $12 \mu \mathrm{L}$ of this mixture was loaded onto a $0.7 \%$ agarose gel. Electrophoresis was conducted at 60 volts in Tris, boric acid, EDTA (TBE) buffer for $2 \mathrm{~h}$. The gel was stained with ethidium bromide $(0.5 \mu \mathrm{g} / \mathrm{mL}$ in DDW) for $20 \mathrm{~min}$ and DNA bands visualized under UV light and photographed using a gel documentation system (Amersham Biosciences, GE Healthcare, UK).

\section{Cell survival (macrocolony) assay in E. coli strains}

Selection of optimum drug dose: Ot or Vc at concentrations of $0,50,100,150,200$, or $250 \mu \mathrm{M}$ of were added to $10^{8} \mathrm{AB} 1157$ bacterial cells (optical density at $600 \mathrm{~nm}: 0.4-0.45$ ) in PBS and incubated for $30 \mathrm{~min}$ at $37^{\circ} \mathrm{C}$. The cells were irradiated on ice with 100 Gy gamma rays, mixed thoroughly, and serially diluted. Dilutions of $10^{4}$ and $10^{5}$ cells were plated on Luria agar in triplicate, incubated at $37^{\circ} \mathrm{C}$ for $24 \mathrm{~h}$ and colonies manually counted under a bacterial colony counter with $1.5 \mathrm{x}$ magnification. Based on the data from this experiment and an earlier study [10], a dose of $200 \mu \mathrm{M}$ of Ot and Vc was used for studying the modification of radiation dose-response in both $\mathrm{AB} 1157$ and MD2130 strains.

Radio-modifying effects of Ot and Vc in AB1157 and MD2130 bacteria: AB1157 and MD2130 E.coli were incubated with DDW, or $200 \mu \mathrm{M}$ of Ot or Vc for $30 \mathrm{~min}$ at $37^{\circ} \mathrm{C}$ prior to irradiation with $0,30,50,100$, or $150 \mathrm{~Gy} \gamma$-rays on ice. The cells were then serially diluted; dilutions of $10^{4}$ and $10^{5}$ were plated in triplicate in Luria agar plates. The cells were allowed to grow for $24 \mathrm{~h}$ at $37^{\circ} \mathrm{C}$ and the visible colonies counted as above.

Surviving fraction $(\mathrm{SF})$ was calculated as the ratio of the average number of colonies in the irradiated group to the average number of cells in the sham-treated control. The dose reduction factor (DRF) was calculated as the ratio of radiation dose resulting in 50\% survival of the vehicle group compared to the radiation dose resulting in 50\% survival in the Ot or Vc treated groups. The data are expressed as mean \pm SEM obtained from three independent experiments.

\section{DNA damage and repair in mouse splenocytes (comet assay)}

$\mathrm{BALB} / \mathrm{c}$ mouse was killed by cervical dislocation and spleen flushed through a nylon gauze (mesh size $45 \mu \mathrm{M}$ ) under sterile conditions to obtain a debris free, single cell suspension. The splenocytes (1x10 cells) were incubated with DDW or $17.5 \mu \mathrm{M}$ (based on a previous work [9]) Ot or Vc for $30 \mathrm{~min}$ before exposure on ice to $4 \mathrm{~Gy}$. Approximately $3 \times 10^{4}$ cells were withdrawn at 0 , $15,30,60,180$, and 360 mins after irradiation and each aliquot mixed with $0.75 \%$ ultralow gelling agarose (BDH Electran; gelling temperature $17^{\circ} \mathrm{C}$ ) on microscopic slides pre-coated with $0.1 \%$ agarose. The slides were cooled on a cooling plate and immersed in pre-cooled neutral lysis buffer (2.5\% sodium dodecyl sulphate [SDS], $1 \%$ sodium sarcosine, 25 mM EDTA, pH 9.5) for 15 min at room temperature and electrophoresed in TBE buffer [ $90 \mathrm{mM}$ Tris, $90 \mathrm{mM}$ boric acid and $2 \mathrm{mM} \mathrm{EDTA} ; \mathrm{pH} 8.3$ ] at $2 \mathrm{~V} / \mathrm{cm}$ for 5 min at $10{ }^{\circ} \mathrm{C}$ in a horizontal electrophoresis unit (Multiphor-II, Pharmacia Biotech, Uppsala, Sweden). Slides were air dried at $45^{\circ} \mathrm{C}$ and stored in a refrigerated humid chamber. Comets were stained with $25 \mu \mathrm{M}$ propidium iodide and examined with a fluorescent microscope (BX60, Olympus) coupled with a CCD camera. Images were acquired and analyzed using a standard Comet assay program (Optimas, UK). Fifty comets per group were analyzed after rehydrating the slides. Tail length, tail movement, percentage of DNA in tail and head of the comet were parameters acquired using the Optimas image analysis software [16]. The percentage of total DNA in comet tail is used as a measure of DNA damage. To quantify the efficiency of Ot and Vc in repairing radiationinduced strand breaks, the cellular DNA repair index (CRI) was applied. CRI for percent tail DNA is defined as the decrease from initial values of percent tail DNA. This relation is utilized to monitor the rate of decrease in DNA damage parameter in irradiated cells under different treatment conditions [17].

$\mathrm{CRI}=\left[1-\left(\right.\right.$ percent tail DNA at time ' $\mathrm{t}$ '/percent tail DNA at initial time $\left.\left.\mathrm{t}_{0}\right)\right] \mathrm{x} 100$

Data from three separate experiments are expressed as mean \pm SEM. 


\section{Statistical analysis}

The data for free radical scavenging activity, survival of $E$. coli and repair kinetics in mouse splenocytes were analyzed by one-way ANOVA and Student's t-test. Each experiment was repeated in triplicate. A value of $p<0.05$ was considered significant. Homogeneity of variance was tested. Radiation dose-response curves were fitted with linear $(\mathrm{Y}=\mathrm{C}+\alpha \mathrm{D})$ and linear-quadratic $(\mathrm{Y}=\mathrm{C}+\alpha \mathrm{D}+$ $\left.\alpha^{2}\right)$ models using Microsoft excel, version 2007.

\section{Results}

\section{Radical scavenging in chemical systems}

Scavenging of DPPH: In the concentration range used in the present studies (62.5 to $250 \mu \mathrm{M})$ both Ot and Vc decreased the absorbance of DPPH at $520 \mathrm{~nm}$ (Figure 1A). At all concentrations used, radical scavenging activity of Ot was higher than that of $\mathrm{Vc}$, although the difference was statistically significant only at $125 \mu \mathrm{M}(\mathrm{p}<0.001)$. The $\mathrm{IC}_{50}$ values for DPPH inhibition by Ot and Vc were $115.48 \mu \mathrm{M}$ and $196.44 \mu \mathrm{M}$, respectively (Table 1).

Scavenging of ABTS: There was a steep decrease in the absorbance of ABTS at $734 \mathrm{~nm}$ induced by Ot and Vc at concentrations of $10-80 \mu \mathrm{M}$ (Figure 1B). Radical scavenging by Ot was significantly higher than that by $\mathrm{Vc}$ at all equimolar concentrations ( $\mathrm{p}<0.001)$ and was associated with an $\mathrm{IC}_{50}$ of $5.49 \mu \mathrm{M}$, compared to $16.47 \mu \mathrm{M}$ for $\mathrm{Vc}$ (Table 1 ).
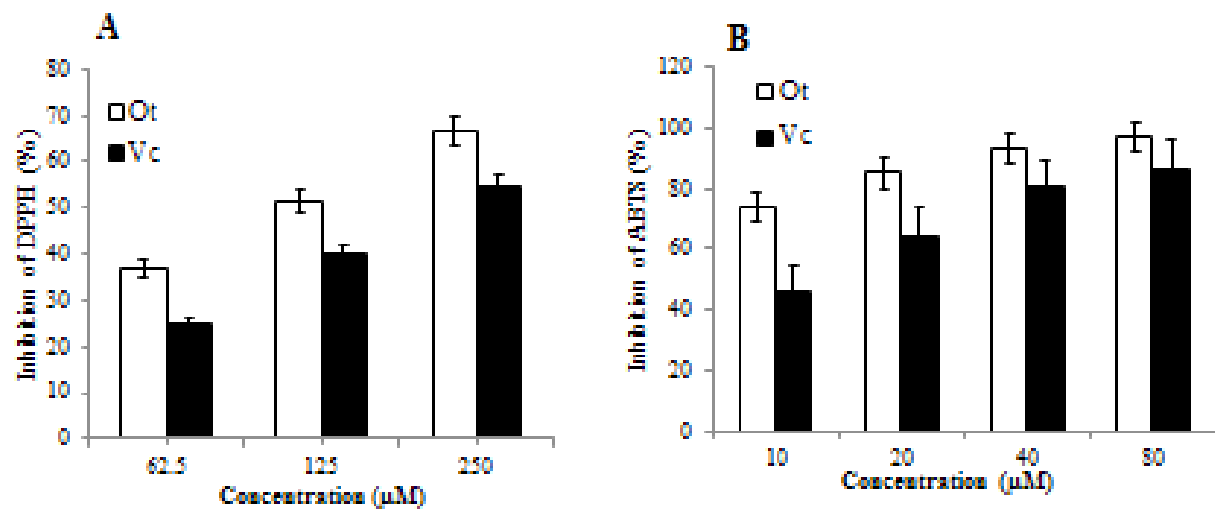

Figure 1: Free radical scavenging activity of Ot and Vc. Inhibition of (A) DPPH and (B) ABTS by Ot and Vc. Data reported as mean \pm SEM from three repeats. ${ }^{* * *} \mathrm{p}<0.001$ compared to $\mathrm{Vc}$ at the same concentration.

\begin{tabular}{|c|c|c|}
\hline Assay & $\begin{array}{c}\text { Orientin } \\
\mathrm{IC}_{50} \pm \mathrm{SE}(\mu \mathrm{M})\end{array}$ & $\begin{array}{c}\text { Vicenin } \\
\mathrm{IC}_{50} \pm \mathrm{SE}(\mu \mathrm{M})\end{array}$ \\
\hline DPPH Assay & $115.48 \pm 5.2^{*}$ & $196.5 \pm 7.5$ \\
\hline ABTS assay & $5.49 \pm 0.5^{*}$ & $14.55 \pm 1.2$ \\
\hline
\end{tabular}

Activity of $\mathrm{O}$ and $\mathrm{Vc}$ in scavenging DPPH and ABTS radicals Table 1: Values are mean \pm SEM of 3 separate experiments. * $\mathrm{p}<0.001$ compared to Vc.

\section{Hydroxyl radical scavenging by the DNA nicking assay}

DNA is prone to oxidation in the presence of reactive oxidative species and will undergo base oxidation and strand scissions in the presence of the radicals generated by Fenton reaction. The antioxidant assay used here is based on the principle that the undamaged supercoiled DNA, which is more compact, will move faster in the gel compared to the plasmid DNA that is attacked by the free radicals and becomes less compact, linear, and which moves slower in the electrophoretic gel. Representative electrophorogram for the plasmid DNA nicking assay is shown in Figure 2, where the migration profile of plasmid DNA reflects the degree of breakage from supercoiled to linear form. The radical species produced by Fenton process disintegrated the native DNA leaving a faint band of Form II DNA (lane 2). Ot or Vc alone at either of the doses used did not have any adverse effect on the plasmid pGEM-7Zf (lanes $3,4)$. Neither flavonoid protected the plasmid in the supercoiled form (Form I), but both Ot (lanes 5) and Vc (lanes 6) protected DNA in the nicked circular form (Form II). These results demonstrate the protective effect of the flavonoids against oxidative damage.

\section{Cell survival (macrocolony) assay in E. coli strains}

a. The preliminary experiment to select the optimum drug dose was performed in the AB1157 strain, exposed to a single radiation dose of $100 \mathrm{~Gy}$. Pretreatment with Ot or Vc increased the survival of 100 Gy $\gamma$-irradiated AB1157 cells in a drug dose-dependent manner. Survival increased with dose $\left(\mathrm{r}^{2}=0.98\right)$ up to $200 \mu \mathrm{M}$ with Ot and Vc. Further increase in drug dose to $250 \mu \mathrm{M}$ did not increase protection (Figue 3). There was no significant difference in clonogenic cell survival with either Ot or Vc. 


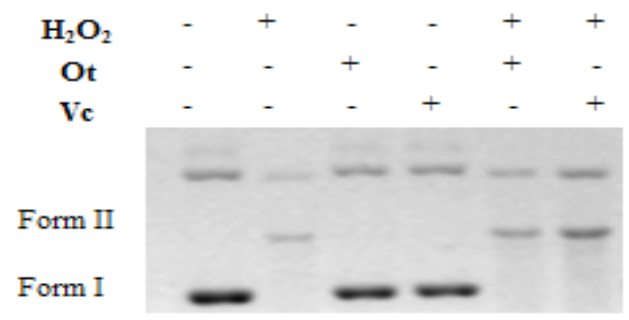

Figure 2: Modulation by Ot or Vc of non-site-specific DNA strand cleavage of plasmid pGEM-7Zf treated with $30 \mathrm{mM}$ hydrogen peroxide. (A) Form I represents the native supercoiled form of the plasmid, Form II is the nicked circular form.

Lane 1: Original DNA

Lane 2: DNA+EDTA $+\mathrm{H}_{2} \mathrm{O}_{2}+\mathrm{FeSO}_{4}+$ Phospate buffer

Lane 3: DNA+ $250 \mu \mathrm{M}$ Ot

Lane 4: DNA + $250 \mu \mathrm{M} \mathrm{Vc}$

Lane 5: DNA+EDTA $+\mathrm{H}_{2} \mathrm{O}_{2}+\mathrm{FeSO}_{4}+250 \mu \mathrm{M} \mathrm{Ot}$

Lane 6: DNA+EDTA $+\mathrm{H}_{2} \mathrm{O}_{2}+\mathrm{FeSO}_{4}+250 \mu \mathrm{Vc}$

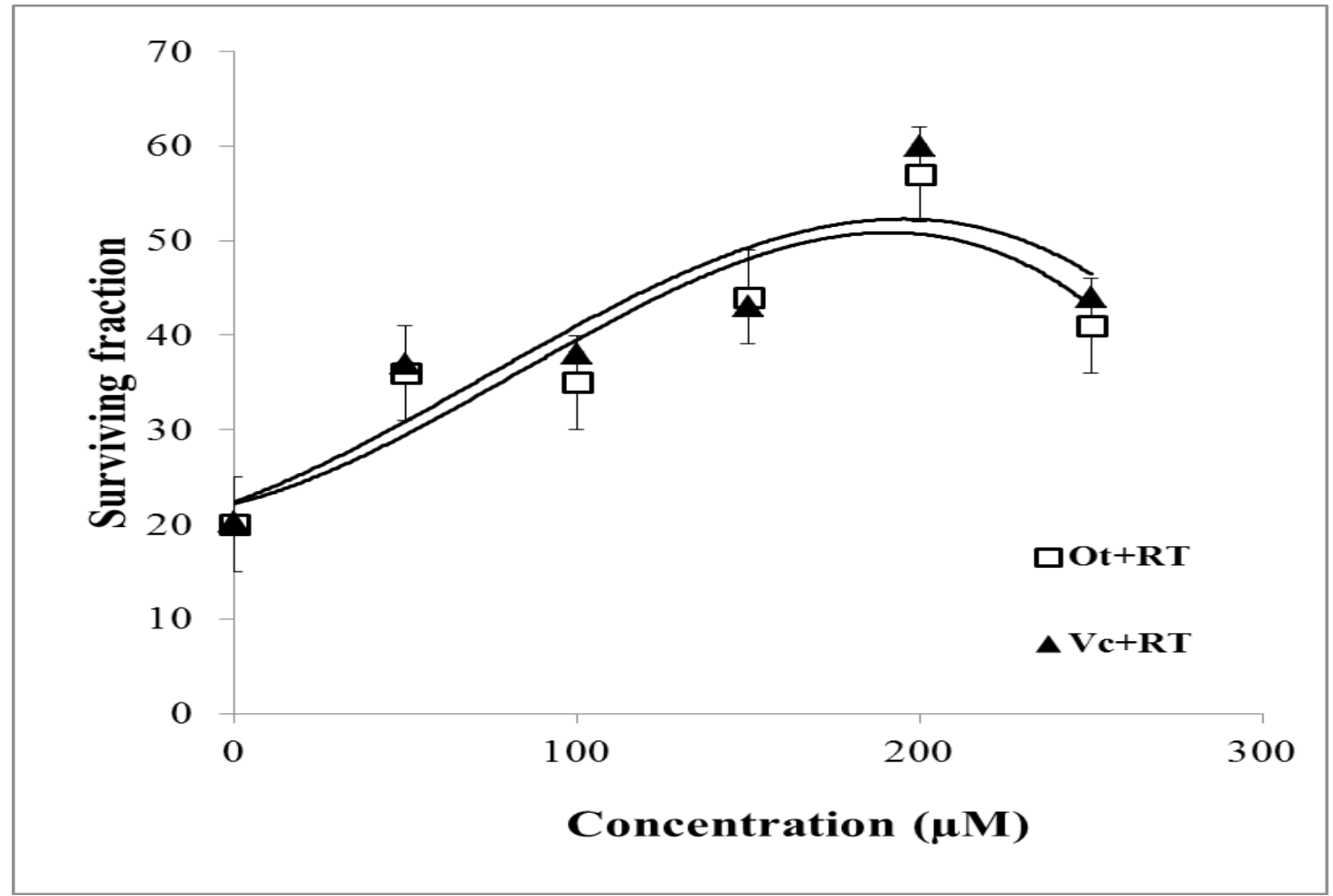

Figure 3: Survival of AB1157 E. coli pretreated with 0-250 $\mu \mathrm{M}$ Ot or Vc before exposure to 100 Gy $\gamma$-rays. The surviving fraction is plotted as a function of drug dose. All values represent mean values of surviving fractions \pm SEM from 3 independent experiments.

b. Ot and Vc $(200 \mu \mathrm{M})$ did not alter the number of colonies in the sham-exposed group indicating that they were non-toxic to the bacterial strain at the applied dose. Irradiation induced a linear dose-dependent decrease in the survival of AB1157 cells resulting in an $\mathrm{LD}^{50}$ of $\sim 40 \mathrm{~Gy}\left(\mathrm{r}^{2}=0.98\right.$; Figure $\left.4 \mathrm{~A}\right)$. Pretreatment with Ot or Vc significantly increased survival at all doses of radiation $(\mathrm{p}<0.01-0.001)$. The survival benefit by the two flavonoids was nearly identical with LD50 of $\sim 85 \mathrm{~Gy}$, resulting in a dose reduction factor (DRF) of $2.12(95 \% \mathrm{CI}=2.10-2.14)$.

c. Ot and Vc by themselves had no impact on the number of colonies in the sham-irradiated repair deficient cells. Irradiation decreased the survival of MD2130 cells at all doses and the dose response was linear-quadratic $\left(r^{2}=0.99\right)$, with survival reducing steeply as the RT dose increased from 30 to 100 Gy. Pretreatment with Ot or Vc significantly (p<0.05, Figure 4B) increased the survival at the lowest RT doses (30 and $50 \mathrm{~Gy}$ ). At higher RT doses (100 and $150 \mathrm{~Gy}$ ) however, increase in survival was not statistically significant $(\mathrm{p}=0.4-0.8)$. The $\mathrm{LD}_{50}$ for the repair deficient strain at $22 \mathrm{~Gy}$, was much lower than LD50 for the AB1157 strain. The LD50 increased to 39 and $42 \mathrm{~Gy}$ for Ot and Vc, respectively, resulting in DRFs of $1.77(\mathrm{CI}=1.75$ and 1.79 for Ot) and $1.9(\mathrm{CI}=1.88-1.92$ for $\mathrm{Vc})$. 


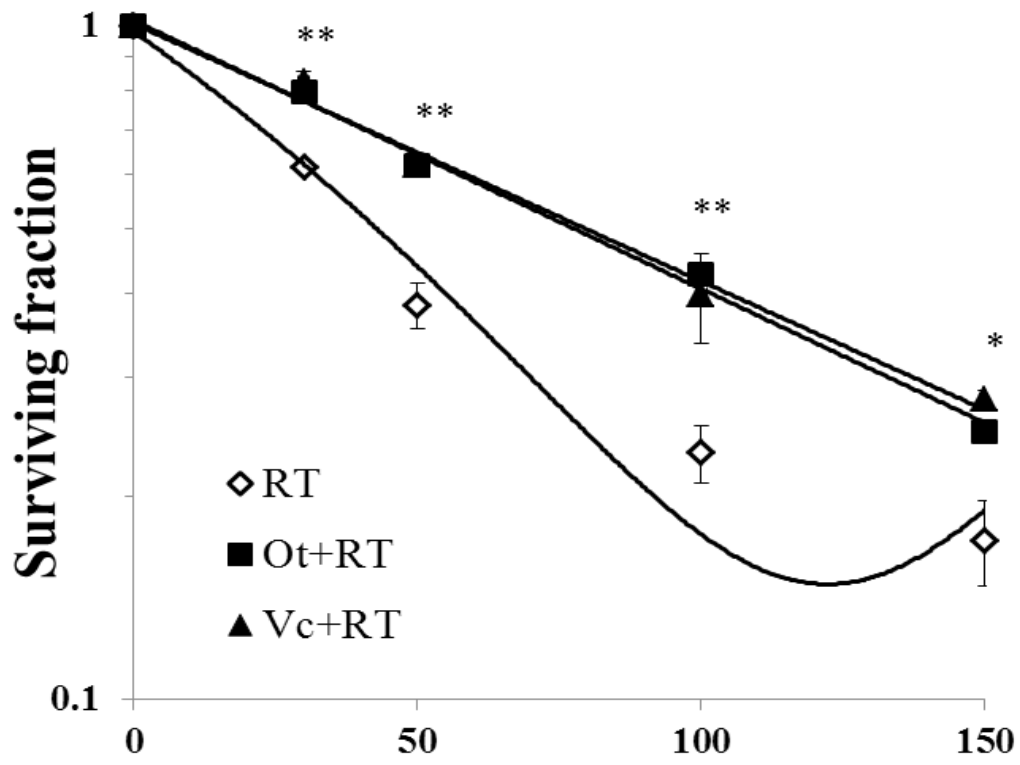

Radiation Dose (Gy)

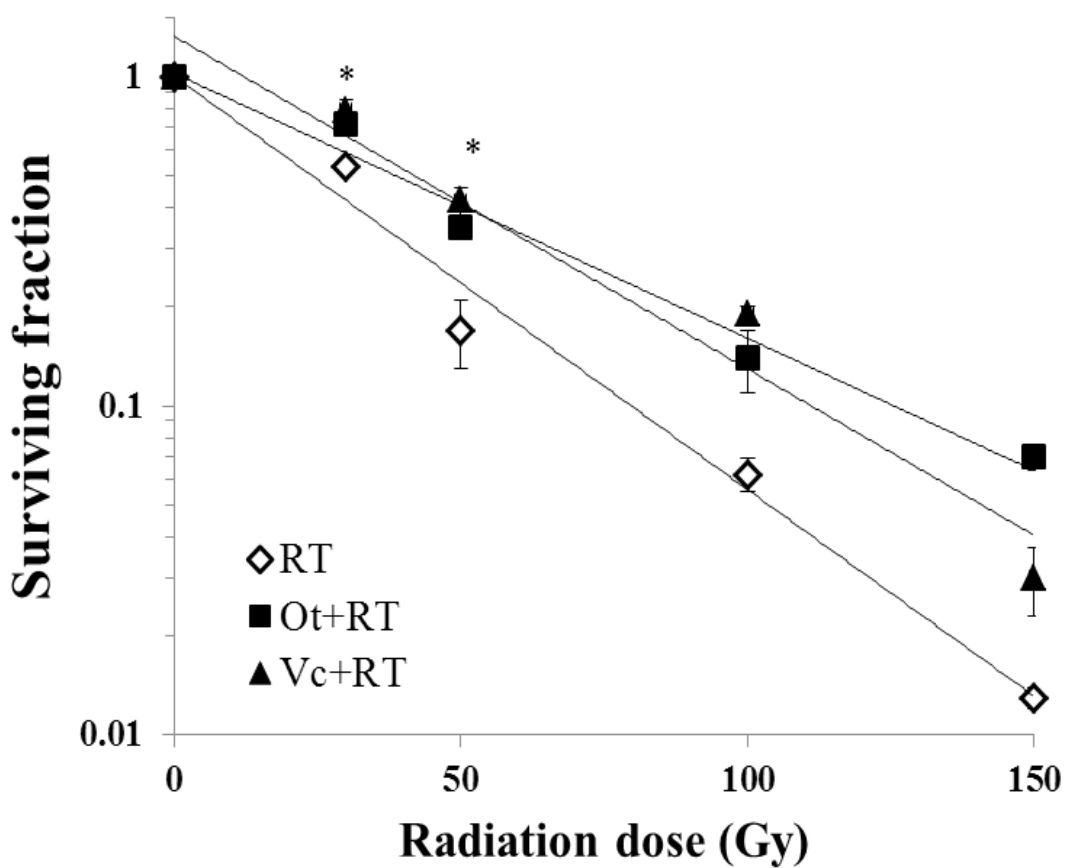

Figure 4: Effect of pretreatment with $200 \mu \mathrm{M}$ Ot or Vc on clonogenic survival of $\gamma$-irradiated bacterial cells. (A) Survival of AB1157 E. coli cells. Curve fitting for radiation alone: polynomial $\left(R^{2}=0.98\right)$; $O t+R T$ and $V c+R T$ : exponential $\left(R^{2}=0.99\right)$. (B) Survival of MD2130 E. coli cells. All survival data were fitted using exponential function; $R T$ alone $\left(R^{2}=0.98\right)$, Ot+RT $(R 2=0.98)$ and $V c+R T\left(R^{2}=0.95\right)$. All values represent mean values of surviving fractions $\pm S E M$ of 3 independent experiments normalized to control values and plotted as a function of radiation dose. ${ }^{*} p<0.05,{ }^{* *} p<0.01$ compared to the irradiated group.

\section{DNA strand break and repair analysis using neutral comet assay}

Exposure of mouse splenocytes to gamma irradiation ex vivo resulted in cellular damage evidenced by increase in tail length, percent DNA in tail, and tail movement of comets. Here, we focus on the percentage of DNA in the comet tail to express damage and subsequent repair of radiation-induced strand breaks. Percent DNA in the comet tail at time 0 (in relation to time of exposure) was used to access induction of initial DNA damage following $4 \mathrm{~Gy}$. The highest increase in percent tail DNA was observed in splenocytes irradiated with 4 Gy immediately after exposure (0 min) (25.37, 95\% CI:21.1-30.3) (Figure 5A). Pretreatment with either Ot or Vc reduced percent DNA in comet tail (16.73, 95\% CI: 12.7-19.4 for Ot and 18.8, CI: 15.8-20.2 for Vc) (Figure 5A), and was significant for Ot $(p<0.01)$ and Vc $(p<0.05)$ compared to 4 Gy-treated splenocytes alone. Although the \% tail DNA for Ottreated cells was lower than the Vc-treated group, the difference was not significant. 
The rates of DNA repair was quantified in the irradiated comets as functions of time post-irradiation. The percentage of DNA in the tail of 4 Gy irradiated comets declined at 15 and 30 min compared to the initial damage, yet remained significantly higher than untreated controls even 180 min post-irradiation, and only returned to baseline values 360 min after exposure. Ot- or Vcpretreated splenocytes demonstrated an earlier decrease in percent tail DNA, reaching baseline values within 60 min after exposure to $4 \mathrm{~Gy}$. These results indicate faster repair in the flavonoid-treated comets compared to slower rejoining of strand breaks in the irradiation alone group.

In order to compare the kinetics of DNA repair in the control and flavonoid treated groups, we estimated the Cellular DNA Repair Index [CRI]. The CRI is a measure of reduced strand breaks and therefore, DNA repair. Our analyses of CRI are indicative of accelerated repair in the Ot and Vc-treated splenocytes. CRI for $4 \mathrm{~Gy}$, Ot+4 Gy and Vc+4 Gy groups were determined at 15, 30, 60, 180, and $360 \mathrm{~min}$ after exposure to gamma rays (Fig 5B). Vc-treated comets demonstrated the highest CRI, followed by Ot-treated comets, while $4 \mathrm{~Gy}$ - irradiated controls had the lowest CRI.

A

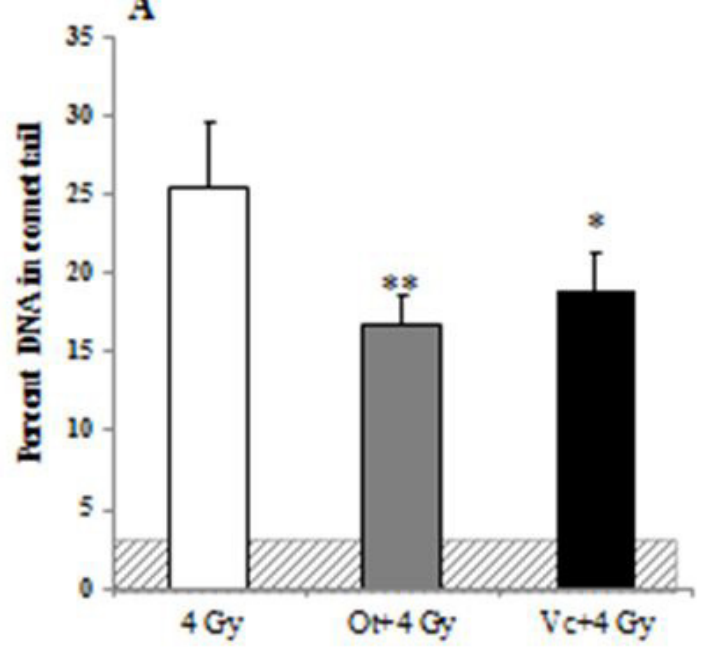

B

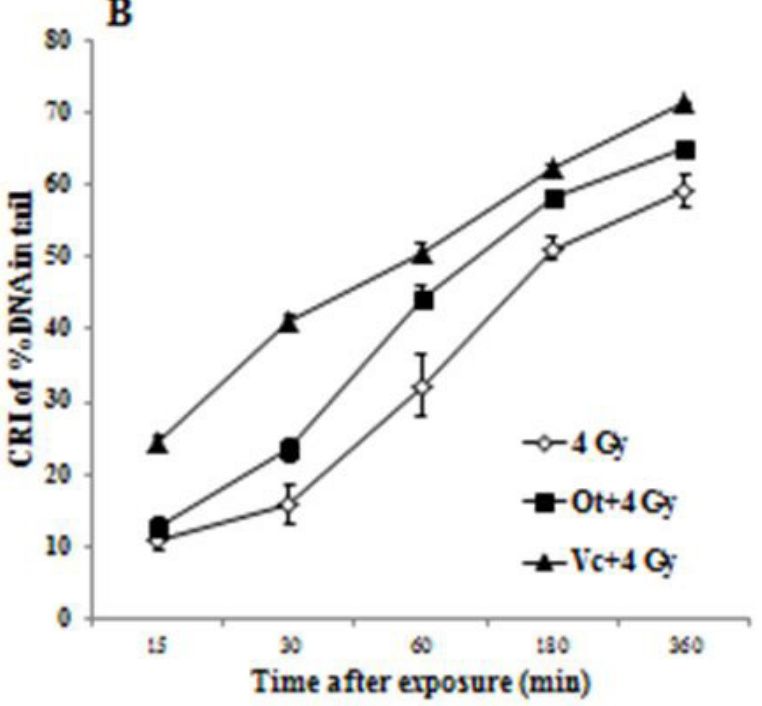

Figure 5: Effect of Ot and $V_{c}(17 \mu \mathrm{M})$ on DNA damage in mouse splenocytes exposed to 4 Gy ex vivo. Fifty comets were scored for each group. (A) Percent tail DNA in splenocyte comets pre-treated with Ot and Vc. Shadowed area represents baseline value. (B) Cellular DNA repair index (CRI) expressing faster DNA repair in flavonoid- treated groups. The data are mean \pm SEM of three separate experiments. ${ }^{*} p<0.05,{ }^{* *} p<0.01$ compared to the irradiated group.

\section{Discussion}

Ionizing radiation causes ionization and excitation of water, leading to formation of water radiolysis products such as hydrated electron $\left(\mathrm{e}_{-}-\right)$, ionized water $\left(\mathrm{H}_{2} \mathrm{O}^{+}\right)$, hydroperoxyl radical $\left(\mathrm{HO}_{2} \bullet\right)$, hydroxyl radical $(\bullet \mathrm{OH})$, hydrogen radical $(\mathrm{H} \bullet)$, and hydrogen peroxide $\left(\mathrm{H}_{2} \mathrm{O}_{2}\right)$ in a very short period of time $\left(\sim 10^{-8} \mathrm{~s}\right)$ in a biological system [18]. These highly reactive free radicals interact with biomolecules resulting in disruption of signal transduction pathways, DNA damage, decreased proliferation and mortality. Flavonoids can prevent injury caused by hydroxyl and other free radicals by directly scavenging the radicals resulting in a stable, inactive form [19]. Data from the present study confirm the antioxidant property of Ot and Vc, and indicate that both flavonoids may have a role in repair of DNA damage.

Two different radical species, DPPH and ABTS, were selected to examine free radical scavenging abilities of the Ocimum flavonoids, Ot (8-C-b-D-glucopyranosyl-luteolin) and Vc (6-C-b-D-xylopyranosyl-8-C-b-D-glucopyranosyl-apigenin). DPPH is a stable free radical with a maximum absorption at $517 \mathrm{~nm}$, which has frequently been used to estimate the antiradical activity of antioxidants [20-22]. The free radical character of DPPH is neutralized in presence of molecules having ability to donate a hydrogen atom. The scavenging of DPPH by Ot and Vc indicate that both flavonoids act by donating hydrogen atom. Similarly, ABTS can also be neutralized by either hydrogen or electron donation. Furthermore, ABTS radicals are more reactive than DPPH radicals; the reactions with ABTS radicals generally take place in less than a millisecond [20]. Both Ot and Vc reduced absorbance of ABTS. The fast reactivity implies that the flavonoids will function better if present at critical sites at the time of radical formation. The most successful radioprotectors studied- aminothiol compounds- are also effective if present in the system at the time of exposure [23], but not when administered after irradiation.

In both DPPH and ABTS assays, Ot demonstrated superior radical scavenging activity to Vc. Protection against hydroxyl radicalinduced plasmid DNA damage by Ot was similarly higher that Vc (discussed next). Luteolin, the parent structure of Ot, is associated with higher antioxidant activity than apigenin, the parent molecule of Vc [24]. Apigenin, with three hydroxyl groups at 5, 7 and 4 ' positions, was associated with a small antioxidant activity, while luteolin, with an additional hydroxyl group at $3^{\prime}$ position, was significantly more protective against oxidative DNA damage in lymphocytes than apigenin [25]. We hypothesize that the presence of a similar hydroxyl group in Ot explains the higher radical scavenging activity observed. 
Protection of plasmid DNA (pGEM-7Zf) in the nicked circular form by both flavonoids appears to be a direct consequence of radical scavenging activity. Under the reaction conditions, hydroxyl radicals generated by Fenton reaction attack DNA guanosine residues, resulting in strand breakage and transformation from native super-coiled form to relaxed circular or linear forms and complete degradation of DNA [26]. Neither Ot nor Vc protected DNA in the super-coiled native form, while both were effective in protecting circular, nicked DNA. This observation is in keeping with direct scavenging action by these flavonoids reported earlier in a chemical system [6,9] and in E.coli [10]. Collectively, DPPH and ABTS radical scavenging assays, and plasmid protection demonstrate that orientin and vicenin are good antioxidants .

In addition, our results on survival of irradiated repair proficient and repair deficient E.coli and comet formation in irradiated murine splenocytes indicate that Ot and Vc may also facilitate repair of DNA damage.

Both repair proficient $(\mathrm{AB} 1157)$ and repair deficient $(\mathrm{MD} 2130)$ strains demonstrated a radiation dose-dependent increase in cellular mortality. However, MD2310 cells were more sensitive to the clastogenic effects of radiation as evidenced by a steep reduction in surviving fractions at $\mathrm{RT}$ doses of $50 \mathrm{~Gy}$ and above, while AB1157 cells showed higher survival at the same radiation doses. Enhanced radiosensitivity of repair deficient strain can be attributed to decreased ability of injured cells to rejoin DNA strand breaks. Pretreatment with Ot or Vc significantly increased survival in both strains; the effect was more pronounced in AB1157 cells (Figure 4A). Increase in survival fraction of MD2310 E. Coli by the flavonoids at lower radiation doses (30 and 50 Gy; Figure 4B) demonstrated that Ot and Vc are effective in protecting bacterial cells against induction of initial lesions, which, if unrepaired, could result in cell death. Neither Ot nor Vc protected MD2310 cells at higher RT doses (100 Gy and above). If these flavonoids functioned only via antioxidant mechanism, there would be no difference in the survival trend for either bacterial strain. In the absence of a competent repair system, the flavonoids could not protect repair deficient bacteria to the same extent as the repair proficient strain. It was reported that radioprotection by cysteamine, an aminothiol, on E.coli cells was almost absent if the cells had genetic defects in the repair systems [27]. The authors inferred that radioprotection by radical scavenging activity for cysteamine was invalid and that specific repair mechanisms may be involved. In contrast, using wild type and radiosensitive (lacking repair pathway) strains of yeast, the radioprotective activity of caffeine was attributed solely to reduction of DNA damage, rather than by interference with repair processes [28]. Here, radioprotection by the ocimum flavonoids appear to be partly by radical scavenging to reduce initial damage and partly by protection/stimulation of inherent repair processes in cells containing active repair machinery.

The dual role of Ot and Vc in reducing initial damage and enhancing repair processes is further established by DNA damage and repair analysis of mouse splenocytes using the comet assay. The comet assay provides a highly sensitive indicator of DNA strand breaks in individual mammalian cells [29]. The presence of Ot and Vc during exposure of the splenocytes reduced DNA damage and facilitated faster repair.. Comet profile at later post-irradiation times as well as CRI indicate that Vc and Ot were more effective in repairing RT-induced damage, while both flavonoids increased repair capacity of the splenocytes compared to 4 Gy-irradiated group.

\section{Conclusions}

The current results demonstrate the efficacy of Ot and Vc as efficient free radical scavengers and modulators of radiation injury. In addition to an antioxidant activity, enhancement of DNA repair by these flavonoids is also indicated. These findings highlight the potential for development of Ot and Vc as radiation protectants.

\section{Acknowledgement}

These data were derived by MS as a Visiting Scholar at Bhabha Atomic Research Center (BARC, Mumbai) and Institute of Nuclear Medicine and Allied Sciences (INMAS, New Delhi). Financial support from the Council for Scientific and Industrial Research (CSIR), Government of India, to MS in the form of Senior Fellowship is acknowledged. Thanks are also due to Professor P.L.N. Rao, former Dean, Kasturba Medical College, Manipal University, India, for extending research facilities.

\section{References}

1. Luthra OS (2010) Ocimum Sanctum (Tulsi): A potent medicinal herb. Pharmacology 1: 1.

2. Nair CKK, Parida DK, Nomura T (2001) Radiation protectors in radiotherapy. J Radia Res 42: 21-37.

3. Weiss JF, Landauer MR (2009) History and development of radiation-protective agents. Int J Radiat Biol 85: 539-73.

4. Singh N, Verma P, Pandey BR, Bhalla M (2012) Therapeutic potential of Ocimum sanctum in prevention and treatment of cancer and exposure to radiation: An overview. Inter J Pharmaceutical Sciences and Drug Research 4: 97-104.

5. Uma Devi P, Ganasoundari A, Rao BS, Srinivasan KK (1999) In vivo radioprotection by ocimum flavonoids: survival of mice. Radiat Res 151: 74-8.

6. Uma Devi P, Ganasoundari A, Vrinda B, Srinivasan KK, Unnikrishnan MK (2000) Radiation protection by the ocimum flavonoids orientin and vicenin: mechanisms of action. Radiat Res 154: 455-60.

7. Uma Devi P, Satyamitra M (2004) Protection against prenatal irradiation-induced genomic instability and its consequences in adult mice by Ocimum flavonoids, orientin and vicenin. Int J Radiat Biol 80: 653-62.

8. Uma Devi P (2001) Radioprotective, anticarcinogenic and antioxidant properties of the Indian holy basil, Ocimum sanctum (Tulasi). Indian J Exp Biol 39: 185-90. 
9. Vrinda B, Uma Devi P (2001) Radiation protection of human lymphocyte chromosomes in vitro by orientin and vicenin. Mutat Res 498: 39-46.

10. Nayak V, Nishioka H, Uma Devi P (2006) Antioxidant and radioprotective effects of Ocimum flavonoids, orientin and vicenin in Escherichia coli. Defense Science Journal 56: 179-87.

11. Logambal SM, Venkatalakshmi S, Dinakaran Michael R (2000) Immunostimulatory effect of leaf extract of Ocimum sanctum Linn. in Oreochromis mossambicus (Peters). Hydrobiologia 430: 113-20.

12. Reshma K, Rao A, Dinesh M, Vasudevan D (2008) Radioprotective effects of ocimum flavonoids on leukocyte oxidants and antioxidants in oral cancer. Indian J Clin Biochem 23: 171-5.

13. Swamy RK, Manickam J, Adhikari JS, Dwarakanath BS (2005) Glycolytic inhibitor, 2-deoxy-D-glucose, does not enhance radiation-induced apoptosis in mouse thymocytes and splenocytes in vitro. Indian J Exp Biol 43: 686-92.

14. Molyneux P (2004) The use of the stable free radical diphenylpicrylhydrazyl (DPPH) for estimating antioxidant activity. Songklanakarin J Sci Technol 26: 211-9.

15. Sanchez-Moreno C (2002) Review: Methods Used to Evaluate the Free Radical Scavenging Activity in Foods and Biological Systems. Food Science and Technology International 8: 121-37.

16. Dwarakanath BS, Zolzer F, Chandana S, Bauch T, Adhikari JS, et al. (2001) Heterogeneity in 2-deoxy-D-glucose-induced modifications in energetics and radiation responses of human tumor cell lines. Int J Radiat Oncol Biol Phys 50: 1051-61.

17. Nair GG, Nair CK (2010) Protection of cellular DNA and membrane from gamma-radiation-induced damages and enhancement in DNA repair by sesamol. Cancer Biother Radiopharm 25: 629-35.

18. Barber DA, Harris SR (1994) Oxygen free radicals and antioxidants: a review. Am Pharm NS 34: 26-35.

19. Nijveldt RJ, van Nood E, van Hoorn DE, Boelens PG, van Norren K, et al. (2001) Flavonoids: a review of probable mechanisms of action and potential applications. Am J Clin Nutr 74: 418-25.

20. Naik GH, Priyadarsini KI, Satav JG, Banavalikar MM, Sohoni DP, et al. (2003) Comparative antioxidant activity of individual herbal components used in Ayurvedic medicine. Phytochemistry 63: 97-104.

21. Scheller S, Wilczok T, Imielski S, Krol W, Gabrys J, et al. (1990) Free radical scavenging by ethanol extract of propolis. Int J Radiat Biol 57: 461-5.

22. Yokozawa T, Chen CP, Dong E, Tanaka T, Nonaka GI, et al. (1998) Study on the inhibitory effect of tannins and flavonoids against the 1,1-diphenyl-2 picrylhydrazyl radical. Biochem Pharmacol 56: 213-22.

23. Maisin JR, Albert C, Henry A (1993) Reduction of short-term radiation lethality by biological response modifiers given alone or in association with other chemical protectors. Radiat Res 135: 332-7.

24. Rice-Evans C, Miller N, Paganga G (1997) Antioxidant properties of phenolic compounds. Trends in Plant Science 2: 152-9.

25. Noroozi M, Angerson WJ, Lean ME (1998) Effects of flavonoids and vitamin C on oxidative DNA damage to human lymphocytes. Am J Clin Nutr 67: 1210-8.

26. Wijewickreme AN, Krejpcio Z, Kitts DD (1999) Hydroxyl scavenging activity of glucose, fructose and ribose-lysone model Maillard products. Journal of Food Sciences 64: 457-61.

27. Bresler SE, Noskin, LA, Stepanova IM, Kuzovleva NA (1978) Mechanism of the radioprotecting action of chemical compounds on Escherichia coli cells. Mol Gen Genet 163: 75-85

28. Vaidya PJ, Pasupathy K (2001) Radioprotective action of caffeine: use of Saccharomyces cerevisiae as a test system. Indian J Exp Biol 39: 1254-7.

29. Wong VWC, SzetoYT, Collins AR, Benzie IFF (2005) The comet assay: a biomonitoring tool for nutraceutical research. Current Topics in Nutraceutical Research 3: $1-14$. 